\title{
Photocatalytic behaviour of anodised titanium using different cathodes
}

Irene González Morán*, Francisco Fernández Martínez**, Mercedes del Río Merino*, Maria Vittoria Diamanti***, MariaPia Pedeferri***, Xiaobo Chen****

*Technical School of Building Engineering, Universidad Politécnica de Madrid, Avenida Juan de Herrera, 6 - 28040, Madrid, Spain

**Technical School of Industrial Engineering, Universidad Politécnica de Madrid, Ronda de Valencia, 3 - 28012, Madrid, Spain

***Department of Chemistry, Materials and Chemical Engineering 'G. Natta', Politecnico di Milano, Via Mancinelli 7 - 20131 Milan, Italy

****Department of Chemistry, University of Missouri-Kansas City, 5100 Rockhill Rd, Kansas City, MO 64110, USA

Corresponding author: irene.gonzalez.moran@alumnos.upm.es; irenegonzalezmoran@gmail.com

Technical School of Building Engineering, Universidad Politécnica de Madrid, Avenida Juan de Herrera, 6 - 28040, Madrid, Spain

Tel.: +3491336 7682; Fax: +34915309244 


\section{Photocatalytic behaviour of anodised titanium using different cathodes}

In the last decades, titanium dioxide $\left(\mathrm{TiO}_{2}\right)$ has been widely researched, because of its applications in photocatalytic environmental pollution removal and in hydrogen generation. Hence, this work deals with the synthesis of titanium dioxide by anodising titanium sheets, however using different cathodes, which may induce differences in the composition and structure of the obtained oxide layers so that these suspected differences can be observed. All specimens were equally thermally treated after anodising to enhance their photocatalytic activity since this step allows the titanium dioxide to crystallise. Their morphology and crystal structure were characterised by X-ray diffraction and FTIR, and optical properties were characterised by ultraviolet-visible absorption spectroscopy. Furthermore, tests of their photocatalytic properties in the degradation of organic dyes were performed in order to have a first evaluation. Indeed, differences in the photocatalytic behaviour of the anodised specimens using different cathodes were found and evaluated.

Keywords: cathode, building, anodising, titanium, photocatalysis, semiconductor

\section{Introduction}

The Air quality in Europe report of 2014 [1] about pollution regulations and impact concerns us about how essential to both environmental and human health clean air is. For instance, air pollution is the main cause of health issues such as asthma, and new policies should be applied in order to avoid the high number of environmentally related deaths around the world [2]. The limiting values of nitrogen dioxide and monoxide, sulphur dioxide, particulate matter and others given by the European Council Directive 2008/50/EC on ambient air quality and cleaner air for Europe [3] are very low with the aim of improving air quality since traffic rates and industrial activities are increasing the pollution worldwide. A promising approach for fighting the problem of nitrogen oxides (NOx) is the photochemical conversion of these oxides to low concentrated nitrates thanks to heterogeneous photocatalytic oxidation using a photocatalyst [4-6]. 
Photocatalysis happens to be a potential answer to air purification, showing the ability of decomposition of organic compounds, sterilisation, self-cleaning among others [7]. Semiconductors such as $\mathrm{TiO}_{2}[8]$ or others like $\mathrm{ZnO}, \mathrm{ZnO}_{-} \mathrm{TiO}_{2}[9], \mathrm{ZrO}_{2}, \mathrm{SnO}_{2}, \mathrm{WO}_{3}$, $\mathrm{CeO}_{2}, \mathrm{Fe}_{2} \mathrm{O}_{3}, \mathrm{Al}_{2} \mathrm{O}_{3}, \mathrm{ZnS}$ and $\mathrm{CdS}[10]$ are used as photocatalysts. During this process, an electron (e-) is excited and jumps from the valence band to the conduction band, creating a positive hole $(\mathrm{h}+)$ in the valence band, as long as the semiconductor absorbs a photon with energy hv larger or equal to its band gap. Moreover, in the presence of water, $\bullet \mathrm{OH}$ radicals are created that together with the positive holes tend to degrade organic compounds such as those found in pollutants and dirt [11]. Besides, the first idea and time of using titanium for the building envelope goes back to 1973 [12], since then its use has increased notably and became especially well-known with the Guggenheim Museum in Bilbao, Spain, probably the most spectacular building cladded with titanium so far [12]. Titanium has, moreover, a great corrosion resistance due to the thin natural film of titanium dioxide that appears on its surface [13]. However, the photocatalytic efficiency of this layer is generally negligible if not absent [14]. Yet, the oxide of this metal may show specific functions that find applications in fields such as biomedicine [6, 15], photovoltaics [16], self-cleaning [17] and environmental purification [5-8]. Interestingly, titanium can be anodised in order to get a thicker and more performing $\mathrm{TiO}_{2}$ layer, whose properties, including photocatalytic activity, depend on its structure, being more efficient if it is in crystalline form like anatase or rutile rather than in the amorphous one [18]. In particular, photocatalytic activity depends on factors such as surface area, crystallinity, phase composition or crystal orientation [19]. Furthermore, anodised titanium presenting a thin oxide layer of more than 300 nanometres presents interference colours that are of particular interest for architectural applications $[20,21]$. 
This idea of first anodising titanium, so that we can take advantage of the potential photocatalytic properties of its oxide layer, titanium dioxide, is quite recent and the simple fact of anodising titanium does not imply or guarantee its efficiency. The composition and morphology of the obtained oxide layer on the titanium surface depend on a variety of parameters and characteristics of the oxidation process, as well as on the used type of titanium or titanium alloy. For instance, it was found out that the use of sulphuric acid as an electrolyte promotes a better photocatalytic efficiency of the samples than using others such as phosphoric acid [20], so that, among all parameters, the type of electrolyte has a very important role. Other known important factors are the applied voltage and current among others. Besides, thermal oxidation is another way of obtaining a titanium dioxide layer, frequently for biomedical purposes and applications $[17,22]$. Different crystalline phases may be obtained, especially by thermal oxidation, among which anatase has a better efficiency [23] regarding photocatalytic behaviour, but a mixture of anatase and rutile in a proper proportion, for instance, the relation of approximately $80 / 20$ (anatase/rutile) that can be found in [24] or in [22], obtains better photocatalytic efficiency than oxides containing only anatase. At the same time, the surface area is also known to play a key role in obtaining highly efficient oxides, as demonstrated by several literature works dealing with the production of nanotubular anodic oxides by anodic oxidation. In this case, the crystal phase most commonly achieved is anatase, and given the high specific surface area - orders of magnitude larger than the nominal one - photocatalytic activity is particularly high $[20,25]$. Yet, this method of fabrication of $\mathrm{TiO}_{2}$ coatings is rather complex and not still suitable for large components, as in architectural applications, where anodising is often performed on sheets that are of dimensions in the order of magnitude of square meters. The same applies to high voltage anodising like anodic spark oxidation procedures, which involve 
very large current densities in order to allow high oxide crystallinity, with both anatase and rutile phases present $[20,26]$. On the contrary, traditional anodising procedures involving the formation of compact oxides can be applied to very large surfaces, and depending on the electrolyte chosen a partial crystallinity may be achieved, in the form of anatase phase [18]. These oxides also present the beneficial aspect of showing interference colours, as previously mentioned.

In this frame, we aim to optimize and simplify the process of obtaining a good photocatalyst in a way never done before to the best of our knowledge, and we present an evaluation of the influence of novel process parameters on the behaviour of anodised titanium presenting both interference colours and photocatalytic activity, as a material of potential interest for the building industry.

\section{Materials and Methods}

\subsection{Growth of titanium dioxide films}

As already mentioned and known before, some factors in the titanium anodising process, like the applied voltage and current or the type of electrolyte, affect the photocatalytic efficiency. However, the type of the necessary cathode for the anodising process had never been taken into account as a possible factor that influences the photocatalytic activity of the oxide layer. The $\mathrm{TiO}_{2}$ films tested in this work come, therefore, from three anodising methodologies with three different cathodes: carbon, titanium and platinum. Moreover, they have been also thermally treated after anodising, at $500^{\circ} \mathrm{C}$ for two hours. All samples were anodised in an aqueous solution of sulphuric acid $0.05 \mathrm{M}$, a maintenance time of one minute was applied after reaching the highest voltage of $60 \mathrm{~V}$ and the applied current amounted to $100 \mathrm{~mA}\left(10 \mathrm{~mA} / \mathrm{cm}^{2}\right)$. Hereinafter, samples are abbreviated as or labelled with the symbol of the 
corresponding cathode and TT for thermal treatment (C TT: anodised with carbon counter electrode, Ti TT: titanium, Pt TT: platinum) as shown in Table 1.

A sheet of titanium (CAS: 7440-32-6 from Alfa Aesar ${ }^{\circledR}$ ) of 1 mm thickness and $99.2 \%$ of purity was cut into discs of 2.5 centimetres in diameter. Afterwards, they were degreased with acetone before the process of electrochemical oxidation. Three replicates of each kind of specimen were prepared. The electrolyte was not stirred during anodising, which was carried out at room temperature.

The pieces of titanium working as the anode were connected to each cathode separately (titanium, carbon and platinum) and to a DC power supply TT PLH120. After anodising, thermal treatments were carried out in an oven in air, since they improve the surface morphology regarding photoactivity [27].

\subsection{Characterization}

Titanium samples were characterised before anodising through X-ray diffraction (XRD) by using a diffractometer X D-5000. Firstly, diffraction has been addressed with $1 \mathrm{~mm}$ thick titanium sheets with $99.2 \%$ purity and 2.5 centimetres diameter, as if they were a powder for the diffractometer. The type of lamp for the radiation was a $\mathrm{Cu}-\mathrm{Ka}$, the applied voltage was $40 \mathrm{kV}$ and the current was $300 \mathrm{~mA}$. Furthermore, their patterns were analysed in the $10^{\circ}$ to $120^{\circ}$ angular range with a $0.02^{\circ}$ step size and counting time of 4 seconds each step. Secondly after anodising, samples were further analysed with a Philips PW3020 using a Cu-K $\alpha$ radiation as well. Diffraction patterns were analysed only in the $20^{\circ}-30^{\circ}$ angular range since it contains both anatase and rutile main peaks. The presence of anatase is shown by the presence of a peak at an angle of $25.5^{\circ}$ and the visible peak at $27.4^{\circ}$ corresponds to rutile phase [28]. SEM analyses were also performed on samples, with a Carl Zeiss AG-EVO ${ }^{\circledR}$ Series 50 instrument. 
UV and visible light spectrum absorbance and Fourier transform infrared (FTIR) analyses were performed using a Cary $60 \mathrm{UV}-\mathrm{Vis}$ Spectrophotometer from Agilent Technologies and a Thermo-Nicolet iS10 FT-IR spectrometer with an attenuated total reflectance unit, respectively.

\subsection{Photocatalysis}

A photocatalysis test is done with titanium samples which have been previously anodised using either carbon or titanium or platinum as the cathode in order to test the differences among them and their efficiency.

This photocatalytic test is based on the degradation of rhodamine-B dye during six hours of irradiation with a lamp whose spectrum is similar to that of natural light. The lamp is an OSRAM ULTRA-VITALUX and its power $300 \mathrm{~W}$, the UV intensity was set to $2.5 \mathrm{~mW} / \mathrm{cm}^{2}$ and measured with a discontinued UM-10 UV radiometer from Konica Minolta. Rhodamine-B [7], like methylene blue and all other dyes, absorbs the visible radiation at given wavelengths: its maximum absorption is at $550 \mathrm{~nm}$. This permits to monitor changes in its concentration due to the $\mathrm{TiO}_{2}$ photoactivity by measuring the variation in its absorbance by spectrophotometry, as explained in previous works [20]. A Rhodamine- $\mathrm{B}\left(\mathrm{C}_{28} \mathrm{H}_{31} \mathrm{ClN}_{2} \mathrm{O}_{3}, \mathrm{RhB}\right.$ hereafter $)$ solution is prepared with concentration $10^{-5} \mathrm{M}$ in distilled water and the photocatalysts samples are immersed in beakers containing $10 \mathrm{ml}$ of this $\mathrm{RhB}$ solution for each measure.

The beakers are covered with a smooth piece of quartz, which not only allows the UV light pass through it but avoids that water evaporated by the heat of the lamp causes a concentration of the RhB solution.

The concentration is measured at 30 minutes intervals in 6 hours starting from time zero (t0). To do this, a Thermo Scientific ${ }^{\mathrm{TM}}$ Spectronic 200 spectrophotometer was used. 


\section{Results and Discussion}

\subsection{Samples anodising}

Differences among the specimens were already noticed in the anodising process, and specifically in the time required to arrive at the desired voltage, which was approximately 1 minute with a titanium or carbon cathode, whereas it was approximately 2 minutes with platinum. Cathode potentials are consistent with the materials used, being carbon and platinum nobler than titanium, while anode potentials only show few tens of $\mathrm{mV}$ of difference, which is a normal value dispersion in different samples of the same material. The observed variation in the oxide growth rate cannot be explained by measured potential values. Table 2 shows the measurements performed on one of the anodising batches, showing that the electrochemical differences observed concern the initial potential of the cathode, which is lower for titanium, and more interestingly the residual current that still flows in the circuit at the final voltage $\Delta \mathrm{Ef}$, i.e., the imposed $60 \mathrm{~V}$. In fact, when $\Delta \mathrm{Ef}$ is reached the oxide grown in presence of the platinum cathode allows a larger current flow, almost double, with respect to those obtained with titanium and carbon, likely indicating higher dissipations in the process such as oxygen evolution, which would justify the longer anodising time as it subtracts current from oxide growth [29]. Higher dissipations are generally associated with an oxide that is not completely amorphous nor stoichiometric, since compositional defectiveness and crystal nuclei would enhance its electronic conductivity and therefore allow oxygen anions to intervene as oxidation process reactant, evolving oxygen as a result. Considering the cathode material, different overpotentials for the cathodic reaction may also be responsible for the higher dissipations. In fact, it is well known that platinum allows very easy hydrogen evolution reactions, meaning that overpotentials for this reaction are rather low compared to other materials. Considering 
that the voltage that builds up in the cell is proportional to reaction overpotentials, following the relationship:

$$
\mathrm{V}=\mathrm{RI}+\eta \mathrm{a}+\eta \mathrm{c}
$$

where $\mathrm{R}$ is the electrolyte resistivity, I the current circulating, $\eta \mathrm{a}$ and $\eta \mathrm{c}$ the anodic and cathodic overpotentials, respectively; and considering that, operating at constant current density, both RI and $\eta$ a terms are constant in the three cases, the only parameter that may change in presence of different cathodes is $\eta c$. Specifically, with Pt lower $\eta c$ values are observed, consequently, the same amount of current flowing in the system will build up a smaller voltage $\mathrm{V}$ across the cell, therefore explaining the need for longer anodising time (i.e., higher overall charge) in presence of Pt electrode when working in a galvanostatic regime.

\subsection{Samples characterization: crystal phase analysis}

The XRD spectra of the specimens previous to anodising only show peaks related to metallic titanium of $\alpha$-phase, as expected due to the use of commercial purity titanium as a substrate for anodising (Figure 1). On the contrary, after anodising also the oxide phases are observed, and specifically, diffraction patterns show the presence of anatase peaks at an angle of $25.5^{\circ}$ (Figure 2). The visible peak at $27.4^{\circ}$ corresponds to rutile phase [28]. There are no big differences among all thermally treated oxides.

SEM imaging of the as anodized sample (Figure 3a) revealed a rather smooth surface, with few small craters due possibly to the fast growth of the oxide and to the beginning of anodic spark deposition phenomena, which are still in a very early stage. The oxide surface was modified after annealing (Figure 3b): in fact, small features appeared on the surface of the oxide, which were interpreted as formation of crystal 
phases, as also attested by XRD. On the other hand, no significant difference was noticed as a function of the cathode employed.

UV and visible light absorbance spectrum of the anodised and thermal treated titanium samples are reported in Figure 4. Spectra of the three different samples are quite similar but different from pure titanium sheet spectrum. Commercially used $\mathrm{TiO}_{2}$ Sigma-Aldrich P-25 has been also tested as a reference, as it is the most commonly used photocatalyst for air and water purification purposes [30, 31]; this oxide, available in the form of nanopowders, contains both anatase and rutile phases. The common absorbance of $\mathrm{TiO}_{2}$ Sigma-Aldrich P-25 is high in the UV-light range, but it decreases with wavelength in the visible light range after a jump in the UV and visible light threshold showing its band gap. In the case of the different samples, the band gaps resulting from the extrapolation happen to be in the range $3-3.2 \mathrm{eV}$, which is coherent with typical crystalline $\mathrm{TiO}_{2}$ band gap values. While P-25 shows a flat absorbance spectrum in visible light, anodised samples present a sinusoidal shape, as observed in the zoom in Figure 4. This depends on the fact that, as mentioned in the introduction, anodic oxides show interference colours, i.e., they are not grey but - in this specific case - present a light blue hue that is caused by interference between the nanometric oxide film and light [29]. It is interesting to observe that the sample that showed the most different behaviour during anodising, i.e., that anodised in presence of platinum cathode, is the one which shows the highest absorbance among anodised ones, meaning that the colour is less intense. The cause may be found in the same differences that led to higher dissipations and longer anodising time, i.e., lower oxide homogeneity, likely caused by compositional and structural defects that would also be responsible for a loss in transparency and, hence, for a decreased colour intensity. 
Additionally, the oxidation state of the anodised titanium surfaces was evaluated by Fourier transform infrared (FTIR) analysis. All anodised samples show a significant peak in the pattern at an approximate wavenumber of $670 \mathrm{~cm}^{-1}$, whereas the pure titanium sample does not follow this behaviour. This peak is characteristic of $\mathrm{TiO}_{2}$ crystallisation in the form of either rutile or anatase. Besides, characteristic peaks of anatase appear on the studied samples at approx. $1630 \mathrm{~cm}^{-1}$ and $2900 \mathrm{~cm}^{-1}$ as well (Fig. 5), confirming XRD results.

\subsection{Photocatalysis}

Photocatalytic performance has been assessed with tests aimed at the degradation of a dyes model pollutant. Figure 6 shows the results of the photocatalysis test done with the three different samples and a reference Rhodamine B solution that did not contain any photocatalyst. This test has been repeated giving good reproducibility.

The mechanism of their photocatalytic activity can be understood as explained in the introduction section. Electrons in the titanium dioxide particles of the samples were excited and jumped from the valence band to the conduction band, since they absorbed photons with energy hv larger or equal to their band gap, in our case in the range 3-3.2 eV, typical of crystalline $\mathrm{TiO}_{2}$ and electron-hole pairs are created. In the presence of water and in the presence of oxygen, hydroxyl $(\bullet \mathrm{OH})$. and superoxide $(\bullet \mathrm{O} 2-)$ radicals were created [27] and both degraded the organic dye of the test verifying the photoactivity of all of the samples. Specifically, they achieved a notable reduction of more than $44 \%$ of dye concentration, comparing to the reference one which obtained a mean of $7 \%$, representing the sole photolysis of the dye due to UV exposure. However, differences among all of them were noticed in the extent of Rhodamine-B degradation. Anodising with platinum counter electrode resulted in the lowest photoactivity, a degradation extent of $44 \%$, and with titanium in the better photoactivity, $74 \%$ of 
degradation. On the other hand, anodising with carbon as a cathode performed a 57\% reduction of the concentration of Rhodamine-B. This means that the counter electrode not only affects the oxide growth rate and defectiveness, which is responsible for higher current dissipations in the process, but also the oxide photoactivity in spite of a similar crystallinity. In this case, it takes approximately 2 minutes to arrive at the desired voltage, as compared to the 1 minute in the other two samples. It is known that the faster the half-reaction that occurs at the auxiliary or counter electrode is, the better for the process (anodising) at the working electrode so that it sounds sensible that the formed oxide layer of the samples anodised with platinum is more defective and therefore, less photoactive due to recombination of charge carriers at the oxide defects. Moreover, samples which showed similar behaviour in the anodising process (with titanium and carbon counter electrodes) also resulted in slightly different photoactivity. The reason could lie in the contamination of the oxide by carbon, partly dissolved in the acid electrolyte used in anodising and could then be incorporated in the oxide during the growth process, therefore affecting its chemistry and, with it, its electronic properties. However, other authors stated that the impurity doping (carbon) probably improved photoactivity under visible light [32].

\subsection{Differences in the photocatalytic behaviour of the samples}

In order to analyse if there are statistically significant differences between the obtained results, a statistical approach is used. Moreover, another batch of samples was performed subsequently (see Table 3 below) and the photocatalysis was as well tested twice to add more data to the statistical analysis.

Specifically, the F-test (Fisher's test) was applied with a 95\% of confidence level, testing the null hypothesis of equality of means. This procedure compares several 
samples and tests whether there are any significant differences amongst them. The Pvalue evaluates how well the data support the argument that the samples have different photocatalytic behaviour if the P-value (Probability value) is lower than 0.05 . The results of this test showed that there is a statistically significant difference between the means of the 4 different samples at the $5 \%$ significance level since the P-value is 0.0002. Furthermore, the Multiple Range Test was applied to determine which means are significantly different from which others, indicating that the six possible pairs show statistically significant differences at the $95.0 \%$ confidence level. The applied KruskalWallis Test obtained a P-value of 0.0012 , which is less than 0.05 and shows as well significant difference amongst the medians at the $95 \%$ confidence level.

\section{Conclusions}

After having coated the different samples and addressed the photocatalysis tests, the following conclusions have been drawn:

- Oxide layers that achieve an important photocatalytic activity are obtained with all of the different treatments.

- All these oxides show a nice and uniform colour which is due to interference phenomena, which makes them even more appealing as environmentally friendly, depolluting materials for architectural applications.

- Differences among samples were found depending on the cathode used in the anodising process, as the hypothesis pointed out. The most efficient sample results to be the one anodised with titanium as a cathode. On the other hand, the samples anodised with platinum as the cathode show the lowest photocatalytic efficiency and at the same time their production requires the highest amount of current, i.e., the least efficient anodizing process. Further investigations are 
needed to better understand this variation in the oxide behaviour, but it appears to be due to the extent of defectiveness of the oxide, which adversely affects photocatalytic activity. This approach can lead to energy savings and economic benefits.

- Future investigations about the photocatalytic activity under visible light of the samples may indicate if they are also efficient in such conditions, which would be of great interest for architectural applications, and to which extent the cathode material influences such behaviour.

\section{Acknowledgements}

This article has been developed within the framework of a $\mathrm{PhD}$ project from the Doctorate Program 'Technologic Innovation in Building' at the Universidad Politécnica de Madrid. The project has been supported by the Department of Polymers of the School of Industrial Engineering and the research group 'Characterization and analysis of materials' and by the School of Building Engineering of Madrid from the Universidad Politécnica Madrid. Special thanks must be mentioned to the Erasmus Program and the Social Council of Universidad Politécnica de Madrid (UPM), which financed stays in Italy and in the United States, and to technicians from the CSIC (Alfonso, Eugenio and Sergio). Moreover, Xiaobo Chen thanks the financial support from the College of Arts and Sciences, University of Missouri - Kansas City.

\section{References}

[1] EEA. Air quality in Europe-Report No 9/2013: ISSN 1725-9177 European Environment Agency [Internet]. Luxembourg: Publications Office of the European Union, 2014 [24/12/2014]. Available from: http://www.eea.europa.eu/publications/air-quality-in-europe-2014

[2] George C, Beeldens A, Barmpas F, et al. Impact of photocatalytic remediation of pollutants on urban air quality. Front Environ Sci. Engin. 2016;10(5):1-11.

[3] Directive 2008/50/EC of the European Parliament and the Council of 21 May 2008 on ambient air quality and cleaner air for Europe. Official Journal of the European Union. 11/6/2008. 
[4] Hüsken G, Hunger M, Brouwers HJH. Experimental study of photocatalytic concrete products for air purification. Build environ. 2009;44(12): 2463-2474.

[5] Zhang Y, Fan W, Du HQ, et al. Study on photocatalytic performance of $\mathrm{TiO}_{2}$ and $\mathrm{Fe}_{3}+/ \mathrm{TiO}_{2}$ coatings. Surf Eng. 2017; 33(11):849-856.

[6] Kim YS, Shin KR, Kim GW, et al. Photocatalytic activity of $\mathrm{TiO}_{2}$ film containing $\mathrm{Fe}_{2} \mathrm{O}_{3}$ via plasma electrolytic oxidation. Surf Eng. 2016;32(6):443-447.[7] Fujishima A, Rao TN, Tryk DA. Titanium dioxide photocatalysis. J Photochem Photobiol C. 2000;1(1):1-21.

[8] Hagen J. Industrial Catalysis: A Practical Approach. Weinheim: Wiley; 2006.

[9] Mani J, Sakeek H, Habouti S, et al. Macro-meso-porous $\mathrm{TiO}_{2}, \mathrm{ZnO}$ and $\mathrm{ZnO}-\mathrm{TiO}_{2}-$ composite thick films. Properties and application to photocatalysis. Catal Sci Tech. 2012;2(2):379-385.

[10] Mo J, Zhang Y, Xu Q, et al. Photocatalytic purification of volatile organic compounds in indoor air: A literature review. Atmos Environ. 2009;43(14):22292246.

[11] Bordes MC, Moreno A. Determinación de la función fotocatalítica de recubrimientos sobre soporte cerámico. [Photocatalytic activity assessment of coatings on ceramics]. Bol. Soc. Esp. Ceram. 2007;46(6):273-279.

[12] Leyens C, Peters M. Titanium and titanium alloys. Weinheim: Wiley; 2003.

[13] Ekoi EJ, Stallard C, Reid I et al. Tailoring oxide-layer formation on titanium substrates using microwave plasma treatments. Surf Coat Technol. 2017;325:299307.

[14] Vera ML, Nuñez J, Ares AE, et al. Oxidación térmica de la aleación Ti-6Al-4V en atmósfera de aire y de oxígeno electrolítico. Primeros avances. [Thermal oxidation of Ti-6Al-4V alloy in air and in electrolytic oxygen. First approaches]. Paper presented at: 2do Encuentro de Jóvenes Investigadores en Ciencia y Tecnología de Materiales; 2008 October 16 - 17; Posadas, Misiones, Argentina. Spanish.

[15] Yavari SA, Necula BS, Fratila-Apachitei LE et al. Biofunctional surfaces by plasma electrolytic oxidation on titanium biomedical alloys. Surf Eng. 2016; 32(6):411-417.

[16] Zhang Z. and Shao G. Reactive close field unbalance magnetron sputter deposition of titanium dioxides for potential photovoltaic applications. Surf Eng. 2017;33(8):642-647. 
[17] Wang L, Sun Y, Gao Y, et al. Preparation of durable underwater superoleophobic Ti6Al4V surfaces by electrochemical etching. Surf Eng. 2016;32(2):85-94.

[18] Brunella MF, Diamanti MV, Pedeferri MP, et al. Photocatalytic behaviour of different titanium dioxide layers. Thin Solid Films. 2007;515(16):6309-6313.

[19] Dikici T, Yildirim S, Yurddaskal M, et al. A comparative study on the photocatalytic activities of microporous and nanoporous $\mathrm{TiO}_{2}$ layers prepared by electrochemical anodization. Surf Coat Technol. 2015;263:1-7.

[20] Diamanti MV, Ormellese M, Marin E, et al. Anodic titanium oxide as immobilized photocatalyst in UV or visible light devices. J Hazard Mater. 2011;186:21032109.

[21] Diamanti MV, Ormellese M, Pedeferri MP. Application-wise nanostructuring of anodic films on titanium: a review. J. Exp. Nanosci. 2015;10(17):1285-1308.

[22] Narushima T, Sado S, Kondo N et al. Evaluation of photocatalytic activity of the $\mathrm{TiO}_{2}$ layer formed on Ti by thermal oxidation. In Sasaki K, Suzuki O, Takahashi N, editors. Proceedings of the 5th International Symposium for Interface Oral Health Science; 2014 Jan 20-21; Sendai, Japan. Tokyo: Springer; 2015. p. 65-78.

[23] Bakardjieva S, Šubrt J, Štengl V, Dianez MJ, Sayagues MJ. Photoactivity of anatase-rutile $\mathrm{TiO} 2$ nanocrystalline mixtures obtained by heat treatment of homogeneously precipitated anatase. Appl Cat B 2005;58:193-202.

[24] Bickley RI, Gonzalez-Carreno T, Lees JS, et al. A structural investigation of titanium dioxide photocatalysts. J Solid State Chem. 1991;92(1):178-190.

25] Paramasivam I, Jha $\mathrm{H}$, Liu N, et al. A review of photocatalysis using self-organized $\mathrm{TiO}_{2}$ nanotubes and other ordered oxide nanostructures. Small. 2012;8:30733103 .

[26] Diamanti MV, Del Curto B, Pedeferri MP. Anodic oxidation of titanium: from technical aspects to biomedical applications. J Appl Biomater Biomech. 2011;9(1):55-69.

[27] Singh J, Khan SA, Shah J, et al. Nanostructured $\mathrm{TiO}_{2}$ thin films prepared by RF magnetron sputtering for photocatalytic applications. Appl Surf Sci. 2017;422: 953-961

[28] Zhang H, Banfield JF. Understanding polymorphic phase transformation behaviour during growth of nanocrystalline aggregates: Insights from $\mathrm{TiO}_{2}$. J Phys Chem B. 2000;104(15):3481-3487. 
[29] Diamanti MV, Souier T, Stefancich M, et al. Probing anodic oxidation kinetics and nanoscale heterogeneity within $\mathrm{TiO}_{2}$ films by conductive atomic force microscopy and combined techniques. Electrochim Acta. 2014;129:203-210.

[30] Ohtani B, Prieto-Mahaney OO, Li D, et al. What is Degussa (Evonik) P25?

Crystalline composition analysis, reconstruction from isolated pure particles and photocatalytic activity test. J Photochem Photobiol A. 2010;216:179-182.

[31] Lu H, Zhao B, Pan R, et al. Safe and facile hydrogenation of commercial Degussa P25 at room temperature with enhanced photocatalytic activity. RSC Adv. 2014;4(3):1128-1132.

[32] Kaneko M, Tokuno K, Yamagishi K, et al. Photocatalytic activity of titanium dioxide powder fabricated from an anodized titanium sheet under ultra-violet and visible light irradiation. Journal of Surface Engineered Materials and Advanced Technology. 2017;7(01):13-23. 


\section{List of tables}

\begin{tabular}{llcccc}
\hline Label & Electrolyte & Voltage-Time & Current & Thermal Treatment & Cathode \\
\hline C TT & Sulphuric acid & $60 \mathrm{~V}-1$, & $100 \mathrm{~mA}$ & $500^{\circ} \mathrm{C}-2 \mathrm{~h}$ & Carbon \\
\hline Ti TT & Sulphuric acid & $60 \mathrm{~V}-1$, & $100 \mathrm{~mA}$ & $500^{\circ} \mathrm{C}-2 \mathrm{~h}$ & Titanium \\
\hline P1 TT & Sulphuric acid & $60 \mathrm{~V}-1$, & $100 \mathrm{~mA}$ & $500^{\circ} \mathrm{C}-2 \mathrm{~h}$ & Platinum \\
\hline
\end{tabular}

Table 1. Overview of the conditions of each sample and their labels

\begin{tabular}{llll}
\hline Cathode & Platinum & Carbon & Titanium \\
\hline Cathode potential at $\mathrm{t}=0$ & $460 \mathrm{mV}$ & $457 \mathrm{mV}$ & $250 \mathrm{mV}$ \\
\hline Anode potential at $\mathrm{t}=0$ & $220 \mathrm{mV}$ & $160 \mathrm{mV}$ & $220 \mathrm{mV}$ \\
\hline Time to reach $60 \mathrm{~V}$ & $2 \mathrm{~min} 16 \mathrm{sec}$ & $1 \mathrm{~min} 3 \mathrm{sec}$ & $1 \mathrm{~min}$ \\
\hline Final voltage $\Delta \mathrm{E}_{\mathrm{f}}$ & $59.7 \mathrm{~V}$ & $58.8 \mathrm{~V}$ & $60 \mathrm{~V}$ \\
\hline Residual current after reaching $\Delta \mathrm{E}_{\mathrm{f}}$ & $57.4 \mathrm{~mA}$ & $34.8 \mathrm{~mA}$ & $37.4 \mathrm{~mA}$ \\
\hline
\end{tabular}

Table 2. Current and voltage measured during the anodising of the different samples

\begin{tabular}{|c|c|c|c|c|c|c|}
\hline \multirow[t]{3}{*}{ Sample } & \multicolumn{4}{|c|}{ Rhodamine B degradation (\%) } & \multicolumn{2}{|c|}{ Statistical data } \\
\hline & \multicolumn{2}{|l|}{ First batch } & \multicolumn{2}{|c|}{ Second batch } & \multirow[t]{2}{*}{ Mean } & \multirow{2}{*}{$\begin{array}{l}\text { Standard } \\
\text { deviation }\end{array}$} \\
\hline & First test & Second test & Third test & Fourth test & & \\
\hline Reference $\mathrm{RhB}$ & 8.6 & 5.4 & 7.1 & 8.1 & 7.3 & 1.4 \\
\hline C TT & 58.1 & 56.0 & 52.0 & 44.1 & 52.5 & 6.2 \\
\hline Ti TT & 75.3 & 73.1 & 63.5 & 72.1 & 71.0 & 5.2 \\
\hline Pt TT & 44.1 & 43.8 & 34.3 & 46.9 & 42.3 & 5.5 \\
\hline
\end{tabular}

Table 3. Overview of the percentage reduction of each sample in the first, second and third test after 6 hours of irradiation 


\section{List of Figures}

Figure 1.

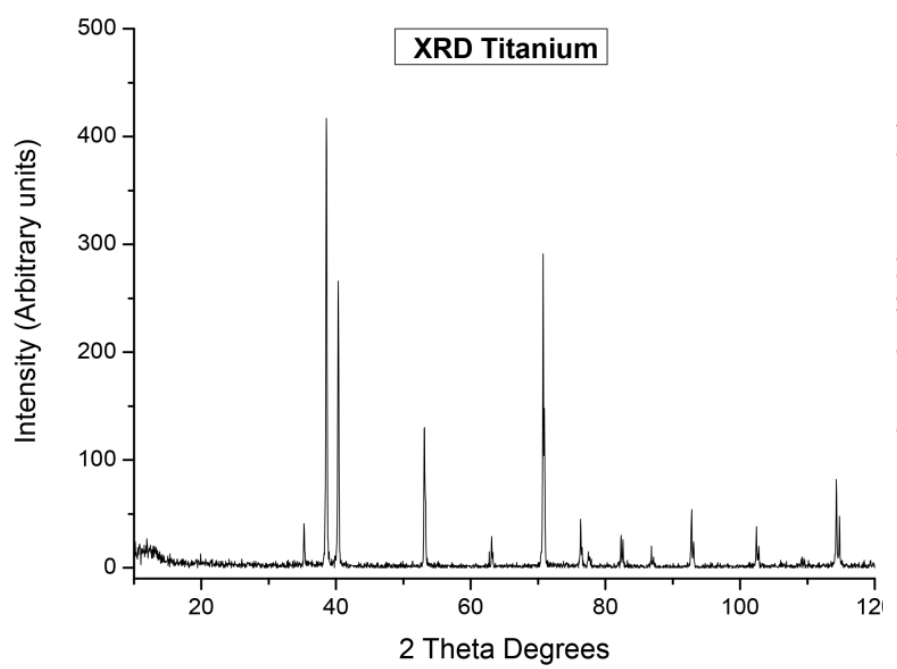

Figure 2.

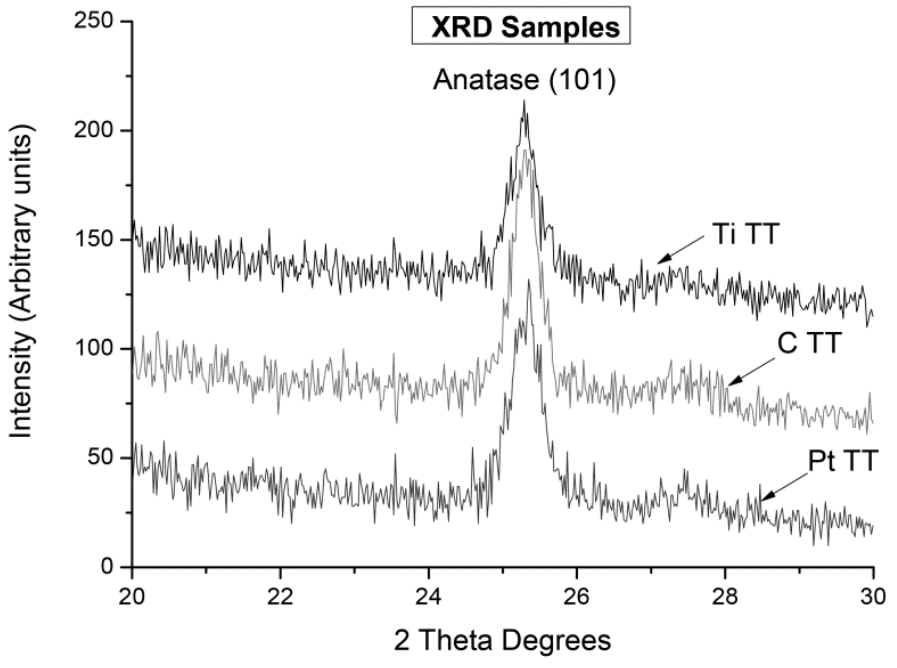

Figure 3.
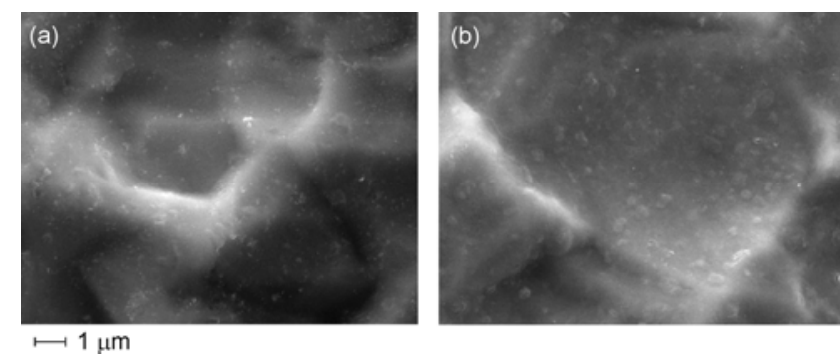

Figure 4.

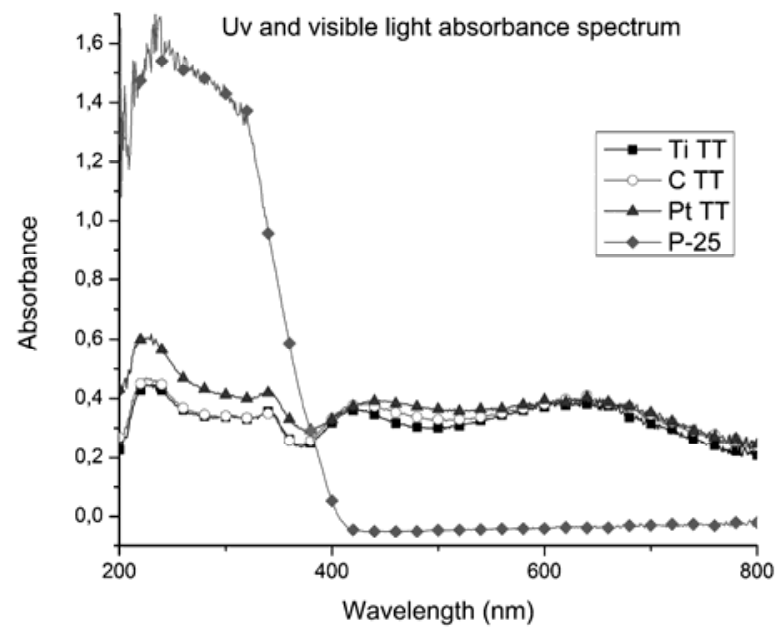

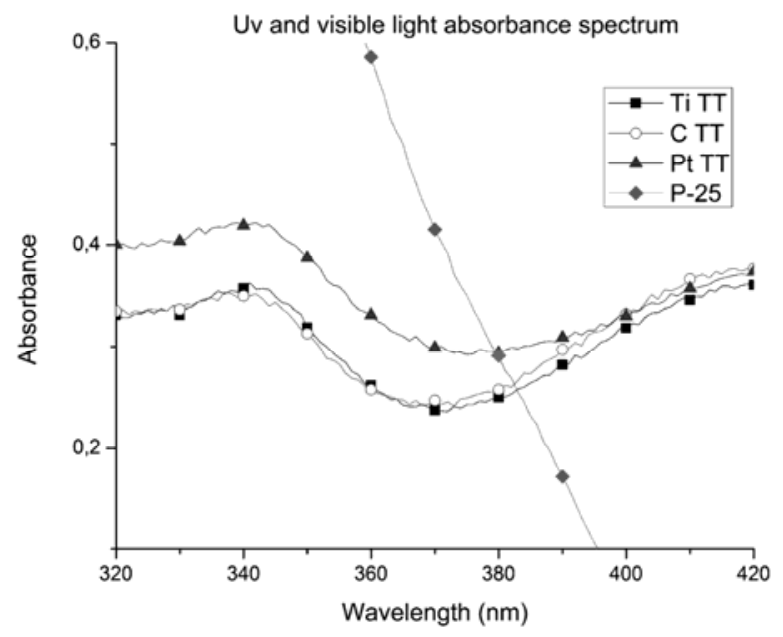


Figure 5.

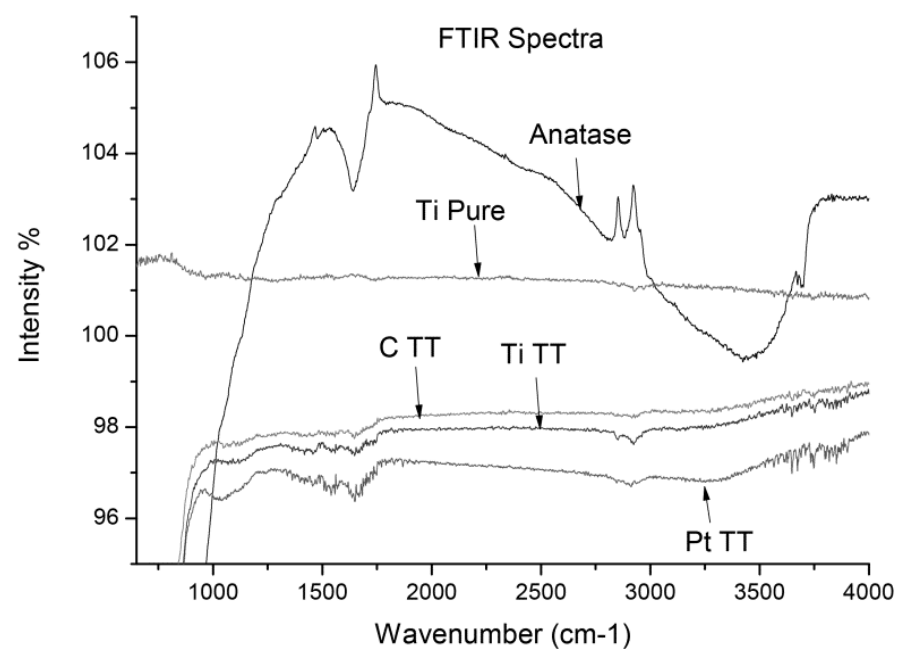

Figure 6.

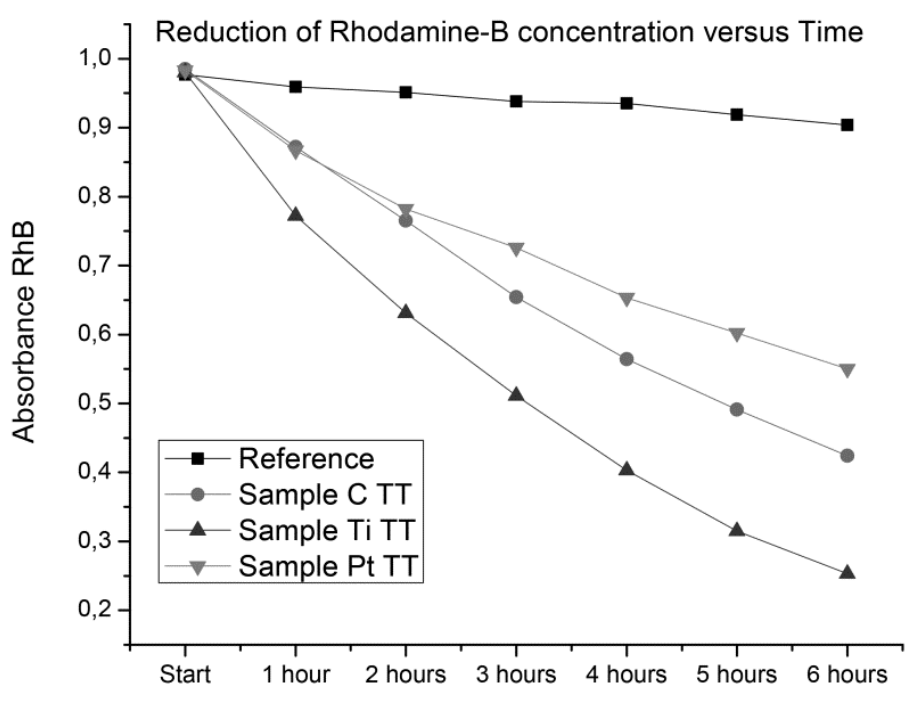




\section{List of figure captions}

Figure 1. X-ray diffraction pattern with the X Siemens D-5000; the ranges in the X-axis go from 10 to 120 grades (angle of diffraction $2 \theta$ ) and the intensity in the y-axis is shown in arbitrary units

Figure 2. XRD pattern of Ti TT, C TT and Pt TT samples

Figure 3. SEM images of anodized sample (a) before and (b) after annealing

Figure 4. UV and visible spectrum of different anodised titanium samples (Ti TT, C TT and Pt TT) comparing to pure titanium and the commercially used $\mathrm{TiO}_{2}$ Sigma-Aldrich $\mathrm{P}-25$

Figure 4. FTIR spectrum of the anodised titanium samples (Ti TT, C TT and Pt TT) comparing to pure titanium and anatase phase crystalline titanium dioxide as comparison

Figure 5. Degradation of Rhodamine B solutions in contact with samples Ti TT, C TT and Pt TT 
